\title{
The TIDieR Checklist Will Benefit the Physiotherapy Profession
}

\author{
Tie Yamato, PhD (cand.), MSc, BSc; Chris Maher; \\ Bruno Saragiotto, PhD (cand.), MPhty, BPhty; Anne Moseley, PhD, PT; \\ Tammy Hoffmann, PhD, BOccThy (Hons1); ${ }^{\dagger}$ Mark Elkins, PhD, MHSc, BA, BPhty; \\ Dina Brooks, $P h D^{\S}$
}

Evidence-based practice involves physiotherapists incorporating high-quality clinical research on treatment efficacy into their clinical decision making. ${ }^{1}$ However, if clinical interventions are not adequately reported in the literature, physiotherapists face an important barrier to using effective interventions with their patients. Previous studies have reported that incomplete description of interventions is a problem in reports of randomized controlled trials in many health areas. ${ }^{2-4}$ One of these studies ${ }^{4}$ examined 133 trials of non-pharmacological interventions. The experimental intervention was inadequately described in more than $60 \%$ of the trials, and descriptions of the control interventions were even worse.

A recent study ${ }^{5}$ evaluated the completeness of descriptions of the physiotherapy interventions in a sample of 200 randomized controlled trials published in 2013. Overall, the interventions were poorly described. For the intervention groups, about one-quarter of the trials did not fulfil at least half of the criteria. Reporting for the control groups was even worse, with around threequarters of trials not fulfilling at least half of the criteria. In other words, for the majority of the physiotherapy trials, clinicians and researchers would be unable to replicate the interventions that were tested.

Describing a treatment may seem like a simple task, but physiotherapy interventions can be very complex. Some interventions are multi-modal, involving the use of manual techniques, consumable materials, equipment, education, training, and feedback. Some interventions are tailored to each patient's specific health state, including the patient's immediate response to the application of the treatment. When the intervention involves a course of treatments, the intensity or dose may be progressed over time. The descriptions of physiotherapy interventions in trial reports often do not capture all these components of the interventions or detail their complexity.
If researchers do not comprehensively report all aspects of the interventions, the trial results cannot be incorporated into clinical practice or the intervention could be implemented incorrectly. Incorrect implementation may make the treatment ineffective, wasting the clinician's and patient's time and health care resources. Inadequate reporting of interventions also poses a barrier to incorporating a trial's results into secondary research such as systematic reviews and clinical practice guidelines, as well as to the usability of these resources. This means that the resources that were invested in undertaking the trial have been wasted. Such resources are extensive, including direct trial costs (e.g., payment of researchers, consumables), use of infrastructure (e.g., clinic space, equipment), human resources (e.g., ethics committee review, granting body review), and the goodwill of patients who agree to participate. Currently, there is a growing realization that we need strategies to reduce waste in clinical research. ${ }^{6}$ When the list of resources involved in a single study is considered, improving the reproducibility of interventions through better reporting could markedly reduce waste in research. ${ }^{7}$

The TIDieR checklist and guide were developed to improve the reporting of interventions in any evaluative study, including randomized trials. ${ }^{8}$ The checklist contains 12 items and was developed as an extension of the CONSORT $2010^{9}$ and SPIRIT $2013^{10}$ statements to provide further guidance for authors on the key information to include in trial reports. TIDieR items include the name of the intervention; intervention rationale for essential elements; intervention materials and details about how to access them; description of the intervention procedures; details of intervention providers; mode of delivery of intervention; location of intervention delivery and key infrastructure; details about the number, duration, intensity, and dose of intervention sessions; details of

From the: *Musculoskeletal Division, The George Institute for Global Health, Sydney Medical School, The University of Sydney, Sydney, N.S.W.; $†$ Centre for Research in Evidence Based Practice, Faculty of Health Sciences and Medicine, Bond University, Robina, Qld., Australia; łInternational Society of Physiotherapy Journal Editor; §Scientific Editor, Physiotherapy Canada.

DOI of original article: http://dx.doi.org/10.1016/j.jphys.2016.02.015

This editorial was originally published in the Journal of Physiotherapy in 2016; however, this article contains a modified author list and amendments to the description of the journal's incorporation of the TIDieR checklist into its manuscript processing. It is republished with the kind permission of the Australian Physiotherapy Association. For citation purposes, please use the original publication details; J. Physiother. 2016; 62:57-58. 
any intervention tailoring; any intervention modifications throughout the study; and details of intervention fidelity assessment, monitoring, and level achieved. The TIDieR checklist will help improve the quality of intervention reporting more if it is used not only by study authors but also by journal editors, peer reviewers, ethics committees, and funding agencies. A copy of the checklist is available at http://www.equator-network.org/ reporting-guidelines/tidier/.

In summary, incomplete reporting of interventions in physiotherapy studies is an important problem, and we endorse the use of the TIDieR checklist as a potential solution. The responsibility for improving intervention reporting extends beyond the authors of individual trials to journal editors and others who can mandate the use of the TIDieR checklist to combat this problem. Mandating the use of the TIDieR checklist would guide authors to describe their interventions better and, consequently, help clinicians to use the interventions and researchers to synthesize and replicate the evidence.

At Physiotherapy Canada, the TIDieR statement has already been incorporated into editorial policy. Submitting authors are required to complete the checklist at the time of submission of a manuscript that describes any study that involves the delivery of an intervention. Authors can download a copy of the TIDieR checklist at http://www.utpjournals.com/blog/wp-content/uploads/ 2016/02/Reporting-Guidelines-3.pdf. Reviewers are encouraged to confirm that the items on the checklist are adequately reported. The journal's editorial team will also check that the items on the TIDieR checklist are adequately reported. Submitting authors with questions about the checklist are invited to contact the journal's editorial team.

\section{REFERENCES}

1. Herbert R, Jamtvedt G, Birger Hagen K, et al. Practical evidencebased physiotherapy. 2nd ed. London: Churchill Livingstone; 2012.

2. Duff JM, Leather H, Walden EO, et al. Adequacy of published oncology randomized controlled trials to provide therapeutic details needed for clinical application. J Natl Cancer Inst. 2010;102(10):7025. http://dx.doi.org/10.1093/jnci/djq117. Medline:20410466

3. Glasziou P, Meats E, Heneghan C, et al. What is missing from descriptions of treatment in trials and reviews? BMJ. 2008;336(7659):1472-4. http://dx.doi.org/10.1136/ bmj.39590.732037.47. Medline:18583680

4. Hoffmann TC, Erueti C, Glasziou PP. Poor description of nonpharmacological interventions: analysis of consecutive sample of randomised trials. BMJ. 2013;347:f3755. http://dx.doi.org/10.1136/ bmj.f3755. Medline:24021722

5. Yamato TP, Maher CG, Saragiotto BT, et al. How completely are physiotherapy interventions described in reports of randomised trials? Physiotherapy. 2016;102(2):121-6. http://dx.doi.org/10.1016/ j.physio.2016.03.001. Medline:27033780

6. Research: Increasing value, reducing waste. Lancet. 2014;383:1-56

7. Ioannidis JP, Greenland S, Hlatky MA, et al. Increasing value and reducing waste in research design, conduct, and analysis. Lancet. 2014;383(9912):166-75. http://dx.doi.org/10.1016/S01406736(13)62227-8. Medline:24411645

8. Hoffmann TC, Glasziou PP, Boutron I, et al. Better reporting of interventions: template for intervention description and replication (TIDieR) checklist and guide. BMJ. 2014;348:g1687. http:// dx.doi.org/10.1136/bmj.g1687. Medline:24609605

9. Schulz KF, Altman DG, Moher D; CONSORT Group. CONSORT 2010 statement: updated guidelines for reporting parallel group randomised trials. BMJ. 2010;340:c332. http://dx.doi.org/10.1136/ bmj.c332. Medline:20332509

10. Chan AW, Tetzlaff JM, Altman DG, et al. SPIRIT 2013 statement: defining standard protocol items for clinical trials. Ann Intern Med. 2013;158(3):200-7. http://dx.doi.org/10.7326/0003-4819-158-3201302050-00583. Medline:23295957

D0l:10.3138/ptc.68.4.GEE

\section{La liste de contrôle TIDieR profitera à la profession de physiothérapeute}

Tie Yamato, Ph. D. (cand.), M.Sc., B.Sc. ; Chris Maher ;*

Bruno Saragiotto, Ph. D. (cand.), MPhty, BPhty; Anne Moseley, Ph. D., P.T. ; Tammy Hoffmann, Ph. D., BOccThy (Hons1) ; Mark Elkins, Ph. D., MHSc, B.A., BPhty ; Dina Brooks, Ph. D. ${ }^{\S}$

Pour le physiothérapeute, la pratique fondée sur les données probantes consiste à incorporer à la prise de décisions cliniques les résultats d'études cliniques de qualité portant sur l'efficacité des traitements¹. Or si les interventions cliniques sont mal présentées dans la littérature, le physiothérapeute peut difficilement les réaliser

Affiliations : *Division musculosquelettique, Institut George pour la santé mondiale, École de médecine de Sydney, Université de Sydney, Sydney, N.S.W.; †Centre de recherche sur la pratique fondée sur les données probantes, Faculté des sciences de la santé et de médecine, Université Bond, Robina, Qld., Australie; $\$$ Société internationale des rédacteurs en chef de revues de physiothérapie; §Directrice scientifique, Physiotherapy Canada. 